\title{
The importance of narrative learning and reflexivity at work with foreigners granted asylum and the context of a non-governmental organization
}

\author{
Lina Grudulaite $^{1}$ and Irena Zemaitaityte ${ }^{1}$ \\ ${ }^{1}$ Mykolas Romeris University, Educational Science and Social Work Institute, Vilnius, Lithuania
}

\begin{abstract}
This paper discusses the importance of narrative learning and reflexivity at work with foreigners granted asylum. The discussed data is from 1 year duration fieldwork at NGO working with refugees in Lithuania. In this paper the examples from 4 narrative portraits of NGO workers are presented. It is argued that narrative learning is an interactive and co-constructed process and there is the need of awareness about the narratives and narrative learning, and how storytelling could be used for effective social work practice. The paper discusses the doctoral research data and explores the links between narrative learning and reflexivity. It is argued that reflecting about their practice critically, the workers can create new narrative identities and better understand and analyse their own identities, values, choices, practices and wider local and international contexts. Therefore, it is important to increase reflexivity and awareness of workers about various contextual factors and discourses, which might be influencing their narratives about their work and refugees, and further research on narrative learning and narratives of NGO workers.
\end{abstract}

Key words - narrative learning, asylum, non-governmental organization.

\section{Introduction}

This paper is based on the doctoral research data about the narrative learning of NGO workers working with refugees in Lithuania. The NGO workers interacting with their clients, colleagues, the researcher, and other people frequently shape their narratives, and adapt them to different audiences. In this article, using the examples from four narrative portraits of NGO workers, it is argued that narrative learning is an interactive and co-constructive process. There is the need of awareness about the narratives and narrative learning and how storytelling could be used for effective social work practice. Storytelling skills and selfreflection are required in daily practice of social workers, and their stories can be used to shape public discourses. Therefore, the links between narrative learning and reflexivity are explored in this article. NGO workers working with refugees can provide valuable inputs for social policy, challenge social injustice and discriminatory practices. Migration issues are frequently discussed in public debates; therefore, workers of NGOs require skills, training and increased awareness about their narratives and narrative learning process to become effective communicators and advocates for social justice. 


\section{Narrative learning of practitioners of a non-governmental organization working with refugees}

On the base of this paper are findings of the doctoral research. The object of the doctoral research is the narrative learning of practitioners of one religious non-governmental organization working with refugees. Narrative learning is associated with a method, where learning occurs using various stories and with a learning process, where the meanings and understandings are constructed through storytelling [1]. People often create the meanings of their experiences by talking about them and constructing understandings about themselves and others by narration [2]. Narratives help employees to construct their professional and personal identities, interpret a variety of personal and work experiences, and exchange their views [3]. During the research project, one-year fieldwork was conducted in one religious NGO in Vilnius, Lithuania. The researcher recorded narrative interactions and observations in the field notes. Seven long narrative interviews were conducted with its workers. In the research, interpretive and social constructionism paradigms, narrative and ethnographic data were used to create 4 thematically rich portraits of NGO workers working with refugees.

\subsection{Narrative portrait as an analytical tool}

Narrative portrait is an analytical tool, which helps to reflect on and interpret not only an individual story and narrative, but also its wider historical, cultural, and social context. Narrative portrait is an analytical method to analyze individual's history and narrative in its broader historical and social context [4]. From the perspective of social constructionism, the narratives are influenced by history of the narrator and the listeners, as well as social and historical context. Therefore, it is important to explore how people understand and articulate their experiences as their understandings might be influenced by history, events, and current context, as that might provide or limit opportunities for practitioners to act in the present [5]. Thematic analysis and methods of social constructionist narrative analysis were used to analyze and discuss the obtained data. Finally, the research revealed various aspects of narrative learning and linked them to the wider context and debates. In this paper, data and segments from narrative portraits were used to discuss and illustrate close links between narrative learning and reflexivity.

\subsection{The choice of research setting and the role of the researcher}

The research was conducted at one non-governmental organization, which works directly with foreigners granted asylum in Lithuania. During research time in 2018-2019, there were only two non-governmental organizations in Lithuania carrying out formal integration services of foreigners granted asylum. Both organizations are large international organizations with extensive international experience working in the areas of asylum and humanitarian aid. In Lithuania, these organizations started working with foreigners granted asylum in 1998. Currently, the organizations developed specialized centres, which work with refugees and other foreigners. Although these centres have some autonomy they are part of larger NGOs, so their goals and missions are influenced by the wider goals and missions of these organizations. One of such centres was chosen for the fieldwork, because the researcher used to work there before starting her research project. Therefore, in that organization she could be considered as an "insider". The choice was motivated by the convenience as the services were based in the same city, where the researcher lived, and by the fact that it is challenging to get access for long-term research in such organizations without previous contacts. The motivation and interest to explore the narratives of workers of such organization was also 
influenced by experiences of the researcher as the practitioner and the activist in the field. The field of the study was constantly defined by the relationship between the researcher and the workers of the chosen NGO. During the narrative research, the researcher was constantly involved in the process of narrative co-construction and in narrative learning together with the research participants, reflecting her own involvement and bias, recording the reflections in her research diary.

\section{Multidimensionality of reflexivity in the narratives of research participants and the researcher}

The narrative data of the research revealed the multidimensionality of reflexivity in the narratives of research participants and the researcher. Interviewed practitioners were using reflexivity to construct their personal narratives about themselves, their work, and people they work with and create meaning to their experiences. Practitioners were questioning their assumptions, reflecting on the changes and inner and practical transformations, which were occurring during their practice at the organization. The researcher was also constantly in a relationship with the research subjects and a part of the narrative learning under study; research narratives were developed and interpreted in a collaboration with research subjects [6]. Therefore, the researcher had to be reflexive and to reflect how she was participating in co-construction of narratives, narrative learning and, how her position, bias might have influenced her collection and interpretations of data. Berger [7] argues that "exploring how researchers in different positions within diverse contexts collect and interpret data has the potential of further illuminating the various aspects and effects of reflexivity and helping deepen our understanding of the multidimensionality of reflexivity". The importance of reflexivity of a researcher is widely recognized as important part of conducting narrative and ethnographic research. Long-term observation of my study participants in the work environment helped to provide a deeper and holistic understanding of their experiences and the social connections between them [8]. The field research helped to understand better how different institutional discourses might have affected the narratives of the organization's employees and the meanings of their experiences. The researcher was combining the autobiographical narrative with the scientific theoretical analysis. Therefore, in her narrative study, not only the narratives of the research subjects and interpretations of their narrative portraits were revealed, but also the active voice of the researcher - her reflexive position, reflections about the research choices and ethical research dilemmas.

\subsection{Links between narrative learning and reflexivity}

During the narrative interviews, the practitioners were examining their life and work stories, their own feelings, values, reactions, and motives for choosing their job, as well as how they see their practice. Narrative knowledge during the interviews was constructed together with the researcher. However, some practitioners were more experienced in storytelling and had many opportunities to revise their stories for different audiences. Their narratives were more elaborative and reflective, other workers were creating new narratives and narrative identities during the interview and expressed that they rarely had opportunities to reflect how their work and personal stories are linked. Some workers developed their narratives quite independently and needed few leading questions, others relied more on the contributions of the researcher to lead the conversation and ask questions. The stories of the NGO workers unfolded in a specific social and organizational setting; their thematic and narrative analysis provided valuable cultural insights about people working with refugees at that organization and their 
narrative learning environment. In narrations, the team had many opportunities to reflect on their work and cases, and jointly search for best practices, try to solve practical dilemmas in team meetings and frequent supervision sessions. Therefore, the narratives of practitioners were rather reflexive. The practitioners were often switching between "I" and "We" voice in their narratives, revealing that their perceptions were frequently challenged and changing in the team environment.

\subsection{Storytelling as work tool in the context of the NGO}

The research data, collected in 2018-2019, revealed that workers, working with refugees in the integration team, were frequently using their narratives and storytelling as work tools to create a positive and empowering relationship with refugees. They tried to act as mediators between wider society and institutions, inspire service users to change or accept certain rules of society and were actively forming discourses about refugees. The employees also used and felt comfortable in using stories before starting their job in the integration team. For example, Camille was a teacher before starting the job, Raminta practiced theatre for long time as a hobby, Migle was a literature student, Asta - a student of Ethnology. Therefore, they were using their previous experiences and frequently used storytelling as work tool with refugees and their colleagues in the context of the NGO. However, the practitioners frequently highlighted challenges in communicating with other institutions and finding compromises. Their narratives reveal that sometimes they feel the need to defend their positions and stand for service users, and face various obstacles. Sometimes they express feelings of disempowerment by negative attitudes, for example, when trying to search for flats for refugees. The workers in their narratives also reflect on contradictions in their narratives between different professional and personal values like empowerment and control, creating community feeling and maintaining personal professional boundaries, devotion to the job and the risks of burnout at work. Raminta reflected that:

there was a transformation for me, when from that unconditional devotion for work and seeing all sorts of positives in that and maybe some people appeared next to me, who helped to look at myself from outside, to adapt to myself and reconsider that it is really very selfish to act like this and maybe it is some 'narcissism' manifestation, not a real desire to help another, because the strong person will help more than the burnt out person.

Migle shared that she has been experiencing burnout during time of the research and that she wanted to terminate her contract but she constructed the problem in her narrative not as personal but structural and used the voice of team:

Well... we try here to the maximum, in fact we try a lot, but there is a lack of people and a lack of translators, and then we get sick, come back and.... and there is still a bunch, a lot of work and it is accumulating.

Therefore, these examples demonstrate that within a small team storytelling was widely used, but narrative diversity existed and the narratives of workers were frequently shaped by personal experiences, training, and team encounters of practitioners.

\subsection{Reflexivity about the discourses shaping the narratives of NGO workers about refugees and their work}

The interviewed workers of NGO had limited experiences in shaping wider policies and participating in wider advocacy initiatives. The intensity of work, burnout often caused changes in the integration team and all interviewed employees were working relatively short time in the organization. The topic of burnout was frequent in the narratives of team members and frequently discussed in supervisions. Frequent changes in the team also resulted in instability 
in practices of the team and its culture. None of the interviewed employees had previous encounters with refugees before starting their job and limited knowledge about the subject. Therefore, their narratives were often shaped by their individual and organizational experiences and wider dominant discourses about refugees in society. Some practitioners admitted having fears and stereotypes about refugees before starting the job, which were formed by dominant discourses and media about refugees, but their perceptions were frequently shaped in practice and having personal encounters with service users. Asta shared her conversation with a supervisor of volunteers before starting her practice with refugees:

I didn't think anything very good about these foreigners, they just asked me, what I like. I said I like to organize events, there are a lot of events there they said... till the last minute I thought if I made the right choice here, I thought maybe I'll go here to work with some terrorists and integrate them. Somehow, I came and when I met the first person somehow all these stereotypes were shattered.

Asta analyzes her practice reflexively and with retrospection. Her narrative reveals that various public discourses about refugees in media and public discourse influenced her preconceptions and fears, when starting her work. The story also reveals various meta-narratives and the broader cultural context in which Asta lives. "The Lithuanian media, similarly to the media of other countries, have a negative image of refugees, and often the difference is that the threats related to refugees in the Lithuanian media are constructed exclusively by Western European societies and do not reflect the real situation in Lithuania." [9] The discourses that are used to talk about refugees are often politicized and stigmatize people with refugee status [10]. People in Lithuania have little knowledge about the real people who have been granted refugee status in Lithuania. Such meta-narratives were reflected in the story of Asta, but having a direct relationship with foreigners granted asylum she was critically evaluating her personal experiences and creating new personal narrative and narrative identity, which contradicts the dominant narrative about foreigners granted asylum in Lithuania. Although, practitioners often were changing their perceptions about refugees in their practice, however certain distancing and otherness were also observed in some narratives of practitioners. For example, Migle in her narratives frequently expressed that she felt sorry for people she worked with:

sincerely, I am sorry for her, she is asked only here and there to sign, neither translation nor anything in the Labour Exchange... such semi-citizens, they are not our citizens, but I do not know, it was really sad for me to see the same thing again today, I am sensitive and sorry that they are just dropped to the organization, and the organization has, well...now they will have more coordinators, they don't deserve it, but somehow we do what we can.

However, Raminta constructs different narrative image of refugees as active agents and the exception from their communities and tries to avoid cultural stereotypes, because of their decision to survive and flee the country:

somehow, we thought that there is something we write off for culture or some other norms, but in reality, these people may in some sense also be the exceptions in their communities, because they made some very decisive decisions, didn't adapt, maybe didn't die because of that and somehow found themselves here. It's probably some kind of stubbornness, maybe again knowing your truth and the need to survive, it's probably reflected in each of those people in one way or another.

Workers often emphasized various cultural elements and differences encountered in practice in their narratives, but also commonalities. The professional power was frequently reflected in the narratives as practitioners were referring to refugees as service users or clients and frequently acknowledged their power to represent, make certain decisions, and have control function in their work. However, the empowerment was frequently mentioned as one of the main goals of practice in their narratives. Therefore, general values and vocabulary 
of social work were influencing their narratives. Various meta narratives and discourses are reflected in the narratives of the practitioners and it important for NGO workers to be reflexive about their narratives and vocabulary they use and what factors and discourses might be shaping their stories and practice.

\subsection{The importance of effective communication and representation in practice}

Reflecting about their practice critically, the workers can create new narrative identities, understand better, and analyze wider local and international contexts. Raminta's narrative reveals a complex relationship between the NGO and state institutions. According to the worker there is a lack of experience in integration of refugees and in collaboration of NGOs and state institutions working in the field Lithuania. She constructs a desired narrative identity of employees as communicators, who could represent needs of people they work with and shape discourses and practices among institutions. Raminta expressed:

I really think that here a relatively very short time passed, the experience nationally is short, well... somehow for that better collaboration, it's clear that the quality of our own work comes from service delivery, but we're in third place somehow. There is no support from those people, who really should perform certain functions, we help them, and very often things turn around. Those institutions that really should do their job direct everything to us. As a result, that integration is not as smooth as it should be. I think that solutionrepresentation, if there is a representative who speaks loud enough about it, is influential enough to hear him/her. Numbers of all sorts of events and opportunities have increased lately and we are discovering opportunities. The experience is accumulating, but there is still a weak spot here, but we can build that contact through employees, maybe not necessarily the management, to invite, talk, meet, so we build some foundations for more professional practice in the future.

Therefore, the practitioner highlights the importance of effective communication and representation for increasing collaboration and improving effectiveness of services.

\section{The importance of awareness about narratives and narrative learning of practitioners, and how to use storytelling effectively to shape public discourses and policies}

The workers frequently have practical knowledge about the daily concerns and challenges of service users and share them in their narratives. Their narrative learning is shaped by their individual value positions, the individual encounters with refugees, conversations in the team and other learning opportunities. Some workers were challenging dominant discourses, highlighting structural discrimination experienced by service users in the country. Migle shared:

When accompanying them to the health centres, sometimes they do not want to accept them and look there from above, well... and there are no translators. There is a lack of translators, and it is the first proof that the institutions do not work well, that they accept people, but we do not have translators, no professionals, you don't even need other proofs. It is clear when kindergartens are needed, you need to make additional requests, demand that kindergarten is provided, but they somehow get away with; if translators would be provided everything would be easier.

The employee highlights the language barriers and lack of understanding and translators as one of structural problems in integration. She is critical about the work of other state institutions and about structural discrimination experienced by service users. She argues 
that structural discrimination also further strengthens negative discourses about refugees and makes it harder for people to integrate and function independently in the society. There was a lack of training or consistent strategy at the organization on how employees could participate in a wider social policy making. Advocacy initiatives and their involvement were frequently reflected in their narratives as consultants of refugees or mediators between refugees and various institutions, individuals in Lithuania. Although only some practitioners had formal qualification of a social worker, all interviewed practitioners identified their practice as social work. However, some workers acknowledged or regretted that they lack skills and knowledge of professional social work and thought that people having the qualification of a social worker were practicing differently. The concepts that are common in social work, such as casework and empowerment were commonly used in the narratives of the workers of the NGO. Practitioners frequently gave presentations, communicating with students, volunteers, friends, and actively participated in shaping public discourses about refugees, as well as acknowledged their role as educators. However, the practitioners of the NGOs rarely identified in their narratives their role as advocates or activists challenging or shaping wider policies in Lithuania or EU. The current events in 2021 in Lithuania related to the increase of asylum seekers highlight the importance of NGO workers participation in wider public debates, shaping policies, therefore, practitioners need to increase their awareness about their narratives and narrative learning and learn, how to use storytelling effectively.

\subsection{Reflexivity, how religious discourses might be shaping narrative learning in organization}

The organization, where the fieldwork was conducted, is a religious Catholic organization. Although the integration centre differed from other departments of the organization and was more secular, the background and mission of organization were influencing the narratives of workers and their stories. The organizational religious context and team environment were also important factors, which were shaping individual narratives of employees. For example, Camille, when encouraged to share her personal story told that she was invited by the priest, and she constructed in her narration the understanding of her job as a call/vocation. Such narration is quite common in a religious discourse. Miglè also emphasised the role of faith in her narrative. Camille paid a lot of attention to the cultural context in which she lives and works, and emphasized the importance of her religious and national identity. She was constantly comparing her religion and culture with religions and cultures of service users. Camille's narrative was characterized by a high narrative intensity, with a lot of analysis and evaluation. Camille was constantly using stories in her daily interactions, but the interview and questions provided more time and space to reflect on her experiences and further elaborate her story. Her narrative was not only retrospective and reflective, but new meanings were also created through storytelling. The narrative of Camille related to the broader search of meaning in her life. She was frequently using religious discourse to construct the narrative about her personal work experiences. Religious discourse was a dominant unifying and constantly recurring thread in Camille's entire narrative about her work. There were no strict boundaries between personal and professional life in Camille's narrative as all experiences related to deeper relationship with God and faith. In her story, God was a living and active figure and her goal was to build deeper relationship with him through her work experiences and relationships. In the environment of the religious organization, such narrative was supported and could flourish and further develop. Camille's narrative revealed her strong religious identity, as well as how it was performed and cultivated in the organization and her job. She also spoke about importance of evangelization. That might have advantages and challenges, when practicing in the multicultural environment working with refugees who have diverse 
backgrounds and religious affiliations. Although, faith-based organizations have a long international history of work with refugees, it is important to be reflexive, how religious identities and narratives might shape practice of social work and how it might be perceived by service users, the majority of whom come from different cultural and religious backgrounds.

The religious discourse was less dominant in the narratives of other workers, but all of the interviewed employees discussed religious discourse at some point of the interview and linked it with their personal stories. Raminta in the narration constructed her image as a non-religious person and she expressed that she had many doubts, when coming to work for a religious Catholic organization. She shared her position openly with other employees of the organization. She was sceptical about some public narratives of the organization and its mission related to evangelization:

It seems to me that what is said in the training, that you are a person of good will, that the aim is to reach out and help, is probably enough, because we work with such very complicated groups of refugees who have left their country for various reasons. For example, the members of a political party, who have suffered because their religion was more radical than the opposition declared at the time, so I don't know if it would be our mission here working with such group to spread the faith. I see such defined commitments that are very important in our work. They are defined when signing an integration agreement with a person, and there is no point in spreading faith, I think that is not a priority for me, nonetheless.

Migle expressed that she had some opposition about the religious discourse of the NGO before starting her job but told that her views changed in the organization, and she started slowly to practice faith. However, the religious discourse was not dominant in her narrative. The presented examples show how the background and mission of the organization might influence the narratives of its workers and their stories and illustrate importance to be reflexive about that.

\subsection{Reflexivity and how gender might influence narratives in NGO}

The themes related to feminism or femininity were also dominant in the integration team. There was gender imbalance in the organization as majority of employees were women. In addition, at the time of the research, only one male worker was working as a translator in the integration team and all narrative portraits were constructed of female workers. Therefore, it influenced what topics were discussed or ignored in the conversations, as well as narrative environment in general. For example, Migle constructed her narrative identity as a feminist. Both Camille and Migle touched the topics related to the role of women in Muslim cultures in their narratives. Such women were frequently portrayed as obedient, caring, being at risk of domestic abuse by men. There is a risk that such feminized character of NGO narratives can create essential constructions of femininity in public representations [11]. Camille reflects about Muslim women:

Women, Muslims, who are without men, who perhaps are more vulnerable, to whom some kind of supposed intelligent, authority or so in their community explains- you don't go there, you don't do something, cover yourself or not, your children do something wrong, despite of such pressure, they go around and take care of all Belarussians, cook for them, take food and feed, and it's very nice thing, but I don't do that. For example. I come home, I lock the door and I'm glad I'm alone and the neighbours, maybe, they would like to chat, and I understand from these people watching them that theirs is a better way than mine.

Camille represents the position of white, Christian, middle class European woman about Muslim women and her narrative might be based on wider cultural stereotypes about Muslim culture and gender roles. Therefore, it is important to be critical and reflexive, what narratives 
are created about people from different cultures as they might create certain essential images and stereotypes about women and refugees in general.

\section{Conclusion}

To summarize, the examples from 4 narrative portraits of practitioners working in NGO with refugees were used to reflect on the links between narrative learning and reflexivity. The narrative data of the research revealed the multidimensionality of reflexivity in the narratives of research participants and the researcher. The topics of migration are frequent in public debates and discourses. The Baltic countries have relatively little experience in narration about migration and refugee integration. However, these topics are getting increased attention by media, politicians, and public. Reflecting about their practice critically, the workers can create new narrative identities, and understand better and analyse their own identities, values, choices, practices, and wider local and international contexts. Therefore, there is the need to research further narrative learning and narratives of NGO workers working with refugees as such workers could become effective advocates and increase public awareness about the topic. However, it is important to increase reflexivity and awareness of workers about various contextual factors and discourses, which might be influencing their narratives about their work and refugees.

\section{References}

[1] I. De Groot. Narrative learning for democratic citizenship identity: a theoretical framework. Journal Educational Review 70(4), 447-464, DOI: 10.1080/00131911.2017.1344191 (2018)

[2] M.C. Clark, NDACE 126, 3-11 (2010)

[3] J. Holmes, DS 7(6), 671-700 (2005)

[4] E. Rodriguez-Dorans. P. Jacobs 23(6), 611-623 (2020)

[5] I.F. Goodson, Developing narrative theory: Life histories and personal representation (Sense Publishers, 2013)

[6] D.J. Clandinin, Engaging in Narrative Inquiry (New York: Routledge, 2016)

[7] R. Berger, Q R, 1-16 (2013)

[8] A. Shah, HAU, 45-59 (2017)

[9] G. Blažytė M. Frėjutė-Rakauskienė, V. Pilinkaitė Sotirovič, OIKOS 1(29), 7-30 (VDU, 2020)

[10] A. Guilfoyle, P. Hancock, Tamara 8, 123-132 (2009)

[11] A. Szczepanikova, JIWS 11(3), 19-33 (2009) 